\title{
IDOSOS NO CENÁRIO DE INCERTEZAS DA PANDEMIA COVID-19: CAMINHOS PARA ESPERANÇA MEDIANTE O CUIDADO INTERGERACIONAL
}

\section{Karina Silveira de Almeida Hammerschmidt' \\ ORCID: 0000-0002-7140-3427 \\ Rosimeire Ferreira Santana" \\ ORCID: 0000-0002-4593-3715}

Susanne Elero Betiolli' ORCID: 0000-0003-4469-4473

Carla de Lima Silva"I ORCID: 0000-0003-2640-9114

Vanusa do Nascimento ${ }^{\text {IV }}$ ORCID: 0000-0003-4141-2784

Luciana Mitsue Sakano Niwav ORCID: 0000-0002-9342-7454

Anderson Abreu de Carvalho ${ }^{\text {vi }}$ ORCID: 0000-0002-4355-1721

'Universidade Federal do Paraná. Curitiba, Paraná, Brasil.

"Universidade Federal Fluminense. Niterói, Rio de Janeiro, Brasil.

"'Universidade Federal de São Paulo. São Paulo, São Paulo, Brasil.

IvUniversidade Federal do Amazonas. Manaus, Amazonas, Brasil.

`Escola de Enfermagem da USP. São Paulo, São Paulo, Brasil.

v'Universidade Federal de Santa Catarina. Florianópolis, Santa Catarina, Brasil.

Autor Correspondente: Karina Silveira de Almeida Hammerschmidtt E-mail:ksalmeidah@ufpr.br

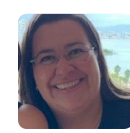

Como citar:

Hammerschmidt KSA, Santana RF, Betiolli SE, Silva CL, Nascimento V, Niwa LMS, et al. Idosos no cenário de incertezas da pandemia covid-19:

caminhos para esperança mediante o cuidado intergeracional. In: Santana RF (Org.). Enfermagem gerontologica no cuidado do idoso em tempos da COVID 19. 2.ed.rev. Brasilia, DF: Editora ABEn; 2020

p 172-177. (Serie Enfermagem e Pandemias, 2). https://doi.org/10.51234/aben.20.e02.c26

\section{INTRODUÇÃO}

Durante as pandemias, a saúde física das pessoas e o combate ao agente patogênico são os focos primários de atenção, com esforço para compreensão dos mecanismos fisiopatológicos envolvidos em propostas para prevenir, conter e tratar a doença' ${ }^{1}$. Embora nessas situações, também deva-se considerar os aspectos envolvidos nas implicações psicológicas, culturais e éticas.

A Coronavirus Disease 2019 (COVID-19), identificada na China no final de 2019, é uma patologia com alto potencial de contágio em que sua incidência aumentou exponencialmente no mundo, sendo considerada uma pandemia ${ }^{2,3}$. A COVID-19 apresenta alta letalidade entre os idosos, especialmente aqueles com doenças crônicas e em idade avançada ${ }^{4}$.

As incertezas sobre a contaminação e o risco de morte do próprio idoso, ou de seus familiares, amigos ou conhecidos podem potencializar estados mentais disfóricos 5 . Essas questões incitam preocupações específicas com a saúde deste público em tempo de pandemia, principalmente relacionadas aos idosos que residem sozinho, aqueles que não dispõe de rede de apoio e cuidadores de outros ${ }^{6}$.

Idosos saudáveis e principalmente aqueles infectados com COVID-19 (ou com suspeita de infecção) podem sofrer reações emocionais e comportamentais, como medo, tédio, solidão, ansiedade, insônia ou raiva, podendo desenvolver alterações psicológicas, que podem suscitar até mesmo em tentativas de suicídio ${ }^{5}$. Esse sofrimento tem chance de ser exacerbado com o distanciamento e/ou isolamento social.

Soma-se a isso o fato do Brasil vivenciar o envelhecimento populacional acelerado, em que os idosos encontram-se em condição de pouca visibilidade e valorização social, partilhando experiências e ações permeadas de preconceito, estigma e estereótipos, imersas no ageísmo ${ }^{6}$. Além disso, os idosos brasileiros perpassam crises econômicas, sociais, de saúde e culturais, principalmente envolvendo aspectos intergeracionais. 
Desse modo é emergente repensar a vida individual e coletiva dos idosos, não somente durante a pandemia, mas vislumbrando cenários futuros, principalmente em relação às necessidades, rede de apoio, humanidade e destino coletivo-planetário. A ressignificação dessas compreensões e ações podem induzir caminhos de esperança, com valorização da cultura do envelhecimento, do cuidado intergeracional, do idoso cidadão, mediante metamorfose do individualismo/ageísmo, promovendo a dignidade humana.

A função e a possibilidade do cuidado intergeracional podem ser manifestadas no reconhecimento de cada geração no outro, como momento evolutivo e fundado na própria existência. Portanto, pertencer a uma mesma geração determina comportamentos e atitudes, logo a geração tem sido utilizada como termo representativo de uma coorte, ou seja, grupos de pessoas nascidas em determinada época e que vivenciam os mesmos acontecimentos.

No entanto, como seria as percepções de cada coorte geracional em relação a fato único ocorrido socialmente - a pandemia da COVID-19. Para tanto, os indivíduos deveriam ser capazes de gerir suas carências e urgências de problemas imediatos, permitindo-se em seguida a buscar objetivos coletivos, conduzindo a organização e planejamento amplo e coletivo - por si intergeracional, ou seja, almejando-se a continuidade do ciclo de vida. Por isso, o caso de sucesso de um idoso que venceu o Coronavirus, fortalece gerações mais novas, assim como, ações de apoio aos idosos em atividades cotidianas enaltecem o valor do idoso na sociedade, e ambos evoluem ${ }^{6}$.

Nesse âmbito, a enfermagem gerontológica é fortalecedora e promotora de ações intergeracionais, repensando os cenários de incertezas frente à pandemia da COVID-19, com ênfase nas condutas de valorização e proteção, conhecimentos científicos em geriatria e gerontologia, e promoção da dignidade do idoso como cidadão no contexto intergeracional.

\section{OBJETIVO}

Refletir sobre o cenário de incertezas que permeia os idosos frente à pandemia da COVID-19, vislumbrando caminhos para a esperança com cuidado intergeracional.

\section{MÉTODO}

Trata-se de texto teórico-reflexivo sobre a pandemia COVID-19, principalmente no cenário de incertezas que permeiam os idosos, alinhado aos possíveis caminhos para a esperança com cuidado intergeracional.

As reflexões foram embasadas em artigos indexados (internacionais e nacionais) relacionados ao tema, bem como em documentos de órgãos oficiais e vivência das autoras. Conjecturam-se dois pilares de reflexão: Idosos no cenário de incertezas frente à pandemia da COVID-19, o qual enfatiza as relações que permeiam a vivência do idoso na sociedade antes e durante a pandemia; e Caminhos para a esperança com o cuidado intergeracional, com abordagem da cultura do envelhecimento, das relações intergeracionais, ressignificação individual e coletiva com ênfase no envelhecimento humano, dignidade e cidadania do idoso, bem como fortalecimento da enfermagem gerontológica nesse contexto.

\section{RESULTADOS}

\section{Idosos no cenário de incertezas frente à pandemia da COVID-19}

A OMS recomenda o protagonismo da pessoa idosa na sociedade, seja em questões sociais, econômicas, políticas, culturais, espirituais e civis. Todavia a pandemia da COVID-19 reforçou a fragilidade das políticas efetivas para o envelhecimento ativo e saudável, promoção à saúde e proteção dos mais fragilizados no Brasil.

Pois, infelizmente, as pessoas idosas têm sido tratadas como fardo para a sociedade, ora pela incapacidade funcional imposta por doenças crônicas; pelo aumentado como população de risco; pelo déficit cognitivo, 
marcado pelo crescente aumento dos casos de demências; pela previdência social insuficiente para vida digna; pela falta de acesso aos serviços de saúde; pelos atos de violência e ageísmo. Portanto, o histórico do Estatuto do Idoso de 17 anos de existência que defende o dever amplo do Estado, da sociedade e da família no cuidado da pessoa idosa ${ }^{7}$, tem iniciativas tímidas sendo realizadas, sobrecarregando a família e não suprindo as demandas de necessidade dos serviços sociais, saúde e segurança.

Em tempo de pandemia da COVID-19, as medidas sanitárias e de distanciamento e/ou isolamento social utilizadas para diminuir o contágio e evitar o colapso do sistema de saúde assentaram os idosos em um risco social dicotômico. Isto é, não consideraram as diversas faces e cenários de vida da pessoa idosa, delegando aos próprios idosos e seus familiares a responsabilidade de provimento e de um cuidado complexo neste momento pandêmico.

Dessa forma, idosos que moram sozinhos e/ou em condições sociais vulneráveis, tornaram-se invisíveis. Os idosos residentes em instituição de longa permanência para idosos (ILPI) se viram aprisionados e sem direito às visitas dos familiares. Aqueles que ainda trabalham, vivenciaram a pressão e consequências de manterem-se afastados das atividades, sem renda complementar, e em vulnerabilidade. Em contraposição, nessa situação complexa de sobrevivência e misto de sentimentos em relação a proximidade da morte observou-se idosos menosprezando a existência da COVID-19, contrariando as recomendações sanitárias e de distanciamento, aumentando ainda mais o preconceito e o ageísmo.

Em meio a essa complexidade planetária, alguns idosos foram tomados por sentimento de tristeza, sensação de abandono e desdenho sobre o viver; outros investiram tempo para contribuir com a sociedade na confecção de máscaras, escudos faciais, cuidando da casa e encorajando os familiares sobre a importância do distanciamento. Para diminuir a saudade ocasionada pelo distanciamento social, alguns idosos reservaram tempo para contar histórias para os netos utilizando recursos de comunicação, outros aprenderam com os familiares a utilizar novas tecnologias/equipamentos e tiveram aqueles que retomaram a realização de atividades de lazer, como artesanatos, leituras, jogos e jardinagem.

Nesse período também afloraram preocupações da sociedade quanto aos idosos, mediante ações solidárias: vizinhos de condomínio colocaram-se à disposição para auxiliar e/ou fazer compras; serviços de saúde se mobilizaram para viabilizar teleatendimento e escuta solidária; redes de supermercados, açougues, padarias e farmácias deram preferência ao serviço de entrega para pessoas idosas ou estabeleceram horários específicos para essa população; associações e instituições sociais distribuíram materiais e alimentos àqueles mais vulneráveis; voluntários serviram comidas para desabrigados, disponibilizaram vestimentas, máscaras e álcool em gel.

Entretanto, mesmo diante de ações positivas, verificaram-se também atitudes negativas e preocupantes, como preconceito, ageísmo, desvalorização, isolamento, exclusão e discriminação do idoso, verificado na diferenciação de classes, na ridicularização do idoso e na infantilização dos cuidados e das necessidades dessa parcela populacional. Citam-se, ainda, hábitos de vida dos idosos arraigados e com dificuldades de mudança, como a compra de mantimentos diariamente, ou a resistência no uso dos serviços de delivery; os conflitos intergeracionais de uso dos recursos de saúde e tecnológicos; imposição para os idosos de decisões ou das escolhas familiares; generalização do ser humano idoso; desvalorização dos conhecimentos específicos sobre geriatria e gerontologia; idosos solitários e/ou que residem sozinhos; ambiente cogeracional passivo para apoio social; exploração financeira do idoso; violências domésticas contra o idoso; responsabilização do idoso como cuidador familiar; e idosos com dificuldades de conhecimentos e acesso tecnológicos?

A preocupação com as incertezas, geradas com a pandemia da COVID-19, aumenta a crise no âmbito social, que tem se qualificado como problema de saúde pública no Brasil e no mundo². Destacando o princípio da ecologia da ação, que assegura atitudes desencadeadas no conjunto do jogo de interações e retroações que envolvem os idosos na sociedade, agregado às demandas inerentes ao momento pandêmico, fortalecidas pela imprevisibilidade das consequências da ação individual e coletiva ${ }^{8}$. A compreensão da hologramaticidade, em que tudo está ligado a tudo, de forma antagônica, concorrente e intercomplementar, permite inferir a complexidade vivida pelo idoso no período da pandemia da COVID-19. 
Neste contexto, as ações, condutas e considerações realizadas no momento atual em relação aos idosos repercutirão nos cenários futuros, principalmente quanto aos cuidados intergeracionais. Desse modo, cabe a cada um fortalecer estas possibilidades, tecendo a proatividade essencial para as relações entre gerações com preservação da autonomia, respeito e dignidade do idoso.

\section{Caminhos para a esperança com o cuidado intergeracional para os idosos}

A pandemia da COVID-19, ao tempo que pode fortalecer ações desfavoráveis para a cultura do enveIhecimento, também pode se constituir em política do bem viver, com revitalização da solidariedade em relação aos idosos, enfraquecendo desigualdades, preconceitos e exclusão, regenerando possibilidades de novos caminhos. Dessa forma, considera-se que a metamorfose dos caminhos para a esperança pode estar permeada pelo cuidado intergeracional dos idosos.

A pandemia reforçou que os idosos necessitam de cuidados específicos, o próprio distanciamento social proposto para protegê-los provocou em alguns o aumento da ansiedade, irritabilidade e agitação. Dessa forma, destaca-se a necessidade do respeito, autonomia, independência e bem viver; possibilitando o cuidado intergeracional dialógico, mantendo a dualidade que associa tempos complementares e antagônicos. Cultivar a rede de apoio ao idoso, pode ser o caminho para obter possibilidades de cenários futuros de valorização e potencialidade para esta população.

Desse modo, o cuidado intergeracional é pautado nas recomendações da Organização Mundial da Saúde aos idosos frente à pandemia da COVID-19, principalmente entre aqueles com declínio cognitivo. É importante promover apoio emocional por meio dos serviços de saúde, mas também pela rede informal, incluindo amigos e familiares, com informações claras e linguagem de fácil compreensão pelos idosos. Práticas de exercícios e rotinas devem ser incentivadas, com ações a serem desenvolvidas pelos idosos junto de seus familiares, no que compete à manutenção da interação e contato regular com entes queridos ${ }^{9}$.

Ao refletir sobre o cuidado intergeracional, é imprescindível considerar a autonomia como determinante do cuidado, e a presença como significante do cuidado. Preservar e garantir a autonomia do idoso perpassa o sentimento de ser cuidado, assim como a presença determinada pela disponibilidade, e pelo estar perto, representa a segurança necessária ao idoso. Ambos os fatores devem estar condicionados ao respeito à totalidade e à complexidade das pessoas aos seus modos de vida e valores culturais ${ }^{10}$.

As incertezas que nos rodeiam sobre o futuro, principalmente aquelas relacionadas à pandemia COVID-19, são inúmeras e envolvem essencialmente a esperança, criatividade, bom senso, responsabilidade, simplicidade e tecnologia. Talvez algumas estratégias aprendidas com a vivência pandêmica indiquem o caminho para fortalecimento da rede de apoio, com comunicação efetiva e constante entre os idosos e seus familiares de maneira segura, mediante utilização de tecnologias.

A remoralização social em relação ao idoso perpassa a responsabilidade e solidariedade, com revitalização das relações intergeracionais, infelizmente, degradadas pela irresponsabilidade, pelo movimento frenético de trabalho, pela hipervalorização da utilidade e jovialidade, e pela amplificação do distanciamento das relações ${ }^{11}$. O cuidado intergeracional revigorado pelo aprendizado pandêmico despreza a rejeição; minimiza escolhas unilaterais; respeita decisões, hábitos e condutas autônomas dos idosos; reduz medidas de residencialização, de proteção exacerbada, de invalidez e de desconhecimento; pois valoriza e considera a sabedoria da vida e das relações. Para tanto, envolve sensatez, pois considera que as vivências dos idosos e conhecimentos foram adquiridos ao decorrer de sua vida, em tempos e momentos diversos.

Diante de período tão singular como a pandemia da COVID-19, a enfermagem gerontológica buscou alternativas para auxiliar e atender os idosos nos diversos cenários; elaborou e divulgou amplamente informações para o cuidado da pessoa idosa; não limitou esforços para compartilhar seus saberes com os demais profissionais e com a sociedade; teceu redes de conhecimento e apoio para o fortalecimento do cuidado à pessoa idosa e da enfermagem brasileira. 
Neste ínterim, a ciência do envelhecimento humano é elemento fundamental para apoio no cuidado intergeracional do idoso, pois abarca com competência técnica e científica conhecimentos sobre a heterogeneidade que envolve os seres humanos idosos. É atuante na luta pelos direitos da pessoa idosa, combatendo o ageísmo, em busca da excelência do cuidado de enfermagem prestados. Envolve-se com afinco em orientações e explicações sobre a saúde individual e coletiva, estando próxima das famílias em suas necessidades, tendo vínculo e aproximação com o idoso e sua rede de apoio.

Na sequência apresenta-se figura esquemática 1, representativa dos elementos envolvidos nos caminhos para a esperança mediante o cuidado intergeracional para os idosos.

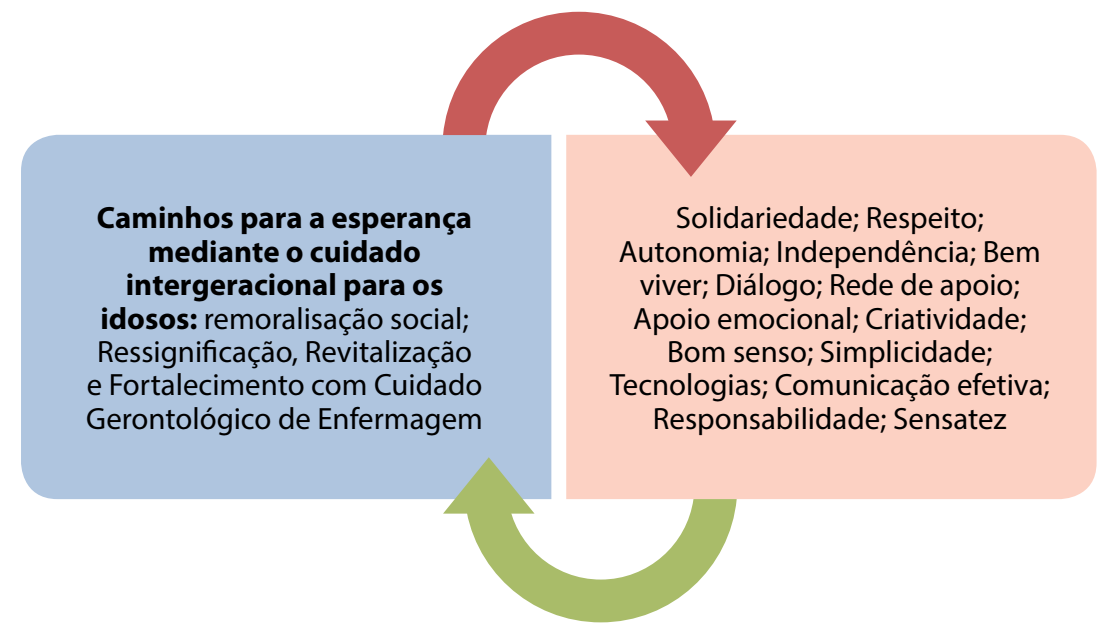

Fonte: Autores, 2020.

Figura 1 - Caminhos para a esperança mediante o cuidado intergeracional para os idosos

Como experiência relevante para motivação e esperança no cuidado intergeracional, destaca-se ações que podem ser propostas para suprir a demanda emocional, fomentar a reflexão e empatia entre idosos ${ }^{12}$. Destaca-se estratégia desenvolvida com residentes em ILPIs, mediante oficinas intergeracionais a distância para confecção de cartas com mensagens de esperança. A mesma proposta, também foi desenvolvida com um grupo de estudantes do ensino fundamental da cidade de São Paulo, que durante o período de distanciamento social tiveram as aulas presenciais substituídas por atividades online.

Mediado por um projeto de extensão universitário, as cartas dos estudantes foram encaminhadas para as ILPI via e-mail, que por sua vez fizeram a impressão e leitura para os residentes. Nesta experiência tanto os estudantes quanto os idosos se encontravam em distanciamento social. Os emitentes das mensagens de esperança, relatam que ao escrever, refletiram sobre a pandemia da COVID 19, pensaram em seus familiares, principalmente avós e/ou parentes idosos e sentiram-se motivados a ter um futuro ressignificado, com superação da pandemia que está sendo vivida. Os idosos das ILPIs, mencionaram sentimento de felicidade, acolhimento, valorização e, esperança ao receber as mensagens escritas pelas gerações mais jovens.

\section{CONSIDERAÇÕES FINAIS}

A pandemia da COVID-19 gerou impacto na sociedade, impondo modificações rápidas na estrutura de serviços e no próprio convívio social (laboral, familiar e de lazer). Ao tempo que envolveu preocupações e incertezas, reforçou a essencialidade do cuidado gerontológico de enfermagem, mediante ações preventivas com ênfase na integeracionalidade. 
Portanto, ações de estímulo da participação social de idosos a distância para interações com as demais gerações, aceitação de ajuda e construção de redes de apoio às situações impostas pela pandemia da COVID-19, incitam importantes reflexões e atitudes positivas com solidariedade, respeito e dignidade ao idoso.

Pois, o distanciamento social, imposto para contenção da pandemia, principalmente para a população idosa, trouxe luz à necessidade de apoio a esta população. Neste âmbito o cuidado intergeracional pode ser aflorado, com gestos de amparo, autonomia, independência; nos quais a família e as gerações mais jovens, podem estar envolvidas visando o bem-estar e proteção do idoso. Quiçá que este possa ser o caminho da esperança para ressignificação dos cenários futuros em relação ao idoso, nos quais ações de valorização, respeito, dignidade, solidariedade possam ser os pilares que sustentam a vida do idoso cidadão.

\section{AGRADECIMENTO}

\section{Ao Departamento Científico de Enfermagem Gerontológica da ABEn Nacional.}

\section{REFERÊNCIAS}

1. Ornell F, Schuch JB, Sordi AO, Kessler FHP. “Medo pandêmico" e COVID-19: ônus e estratégias de saúde mental. Braz. J. Psiquiatria [Internet]. 2020 junho; 42 (3): 232-235. Disponível em: http://www.scielo.br/scielo. php?script=sci_arttext\&pid=S1516-44462020000300232\&lng=en. Epub 03 de abril de 2020. Doi: https://doi. org/10.1590/1516-4446-2020-0008

2. World Health Organization. Coronavirus disease (COVID-19) situation dashboard. Geneva: WHO; 2020. Disponível em: https://covid19.who.int/

3. Brasil. Ministério da Saúde. Painel de casos de doença pelo coronavírus 2019 (COVID-19). 2020. Disponível em: https:// covid.saude.gov.br/

4. Lloyd-Sherlock P, Ebrahim S, Geffen L, Mckee M. Bearing the brunt of covid-19: older people in low and middle income countries. BMJ [Internet]. 2020; 368. Disponível em: https://www.bmj.com/content/368/bmj.m1052. Doi: https://doi. org/10.1136/bmj.m1052.

5. $\quad$ Shigemura J, Ursano RJ, Morganstein JC, Kurosawa M, Benedek DM. Public responses to the novel 2019 coronavirus (2019$\mathrm{nCoV}$ ) in Japan: mental health consequences and target populations. Psychiatry Clin Neurosci. 2020 Feb; 74 (4): $281-82$. Disponível em: https://onlinelibrary.wiley.com/doi/full/10.1111/pcn.12988. Doi: 10.1111/pcn.12988.

6. Santana RF, De Souza MT, Santo FHE, Silva ED, Martins NH (2015). Youth Participation in Home Care for the Elderly. J Gerontol Geriat Res S3:006. doi:10.4172/2167-7182.S3-006

7. Brasil. Ministério da Saúde. Estatuto do Idoso. 3. ed., 2. reimpr. - Brasília : Ministério da Saúde, 2013. 70 p. ISBN 978-85-3341845-5 1. Disposições preliminares, artigo 3.

8. Hammerschmidt KS de A, Santana RF. Saúde do idoso em tempos de pandemia Covid-19. Cogitare Enferm. [Internet]. 2020; 25. Disponível em: https://revistas.ufpr.br/cogitare/article/view/72849. Doi: http://dx.doi.org/10.5380/ ce.v25i0.72849

9. Morin, E. Introdução ao Pensamento Complexo. Porto Alegre: Sulina; 2011.

10. World Health Organization. Mental health and psychosocial considerations during the COVID-19 Outbreak. Geneva: WHO; 2020. Disponível em: https://www.who.int/docs/default-source/coronaviruse/mental-health-considerations.pdf

11. Flores GC, Borges ZN, Denardin-Budó ML, Mattioni FC. Cuidado intergeracional com o idoso: autonomia do idoso e presença do cuidador. Rev. Gaúcha Enferm. (Online). 2010; 31(3): 467-74. Disponível em: http://dx.doi.org/10.1590/ S1983-14472010000300009

12. Hessel S, Morin, E. O caminho da esperança. Rio de Janeiro: Bertrand Brasil; 2012. 